\title{
A Comparative Study Between Laparoscopic Management of Ectopic Pregnancy and Laparotomy: Experience in Tertiary Care Hospital in Bangladesh: A Prospective Trial
}

\author{
Samsad Jahan ${ }^{*}$ \\ Tripti Rani Das ${ }^{2}$ \\ Samira Humaira Habib ${ }^{3}$ \\ Akter Jahan ${ }^{4}$ \\ Mahjabin Joarder ${ }^{5}$ \\ Nurun Nahar ${ }^{6}$ \\ Manisha Banarjee ${ }^{7}$ \\ 'Department of Gynecology \& Obstetrics \\ BIRDEM, Dhaka, Bangladesh. \\ ${ }^{2}$ Department of Gynecology \& Obstetrics \\ BSMMU, Dhaka, Bangladesh. \\ ${ }^{3}$ Health Economics Unit \\ BADAS, Dhaka, Bangladesh. \\ ${ }^{4}$ Govt. Homeopathic College \\ Dhaka, Bangladesh. \\ ${ }^{5}$ Department of Gynecology \& Obstetrics \\ Bangladesh Medical College, Dhaka, Bangladesh. \\ ${ }^{6}$ Department of Gynecology \& Obstetrics \\ Comilla Medical College, Comilla, Bangladesh. \\ ${ }^{7}$ Department of Gynecology \& Obstetrics \\ Dhaka Medical College Hospital, Dhaka, Bangladesh.
}

Correspondence to:

\section{Dr Samsad Jahan}

Associate Professor and Consultant Department of Gynecology \& Obstetrics Ibrahim Medical College \& BIRDEM, Dhaka 122 Kazi Nazrul Islam Avenue, Dhaka -1000, Bangladesh. Mobile : 880-01817049292

E-mail: shellybirdem@yahoo.com; dhcdp@dab-bd.org

\begin{abstract}
Objectives: To compare the efficiency and surgical morbidity associated with laparoscopic management of tubal ectopic pregnancy (EP) compared with that of open laparotomy. Materials and methods: During November 2008 to October 2012, there were 89 with a confirmed ectopic pregnancy These patients were admitted through emergency or outpatient department and managed by laparoscopy (number 70) and by laparotomy (number 19). The diagnosis of ectopic pregnancy was based on history, clinical symptoms, physical examination, a positive serum B-human chorionic gonadotropin (B-HCG), transvaginal ultrasonography. Patients were informed pre-operatively about the surgical procedures. The main outcome measured included operative time, blood loss, and complications. Results: Laparoscopic surgery gives an overall success rate of $98.9 \%$. Linear salpingostomy was the main procedure performed in both groups. Estimated blood loss was significantly lower in the laparoscopy group compared with laparotomy group $(\mathrm{p}<0.001)$. Only $3(3.81 \%)$ patients in the laparoscopy group required blood transfusion, whereas $16(74.94 \%)$ in the laparotomy group needed transfusion $(\mathrm{P}<0.0001)$. The duration of operation in laparoscopy group was $53.2 \pm 16.8$ minutes and $84.5 \pm 30.3$ minutes in the laparotomy group. The duration of hospitalization was significantly shorter in the laparoscopy group $1.12 \pm 0.5$ days compared to $5.25 \pm 0.1$ days in the laparotomy group $(\mathrm{p}<0.0001)$. $)$. In the laparoscopy group $57(72.4 \%)$ patients did not need analgesia after surgery compared with laparotomy group where all the patients needed analgesia. Conclusion: Laparoscopic treatment (Salpingostomy or Salpingectomy) of EPs offers major benefits superior to laparotomy in terms of less blood loss, less need for blood transfusion and postoperative analgesia, a shorter duration of hospital stay. Laparoscopic management of ectopic pregnancy might be the most beneficial procedure with maximal safety and efficacy.
\end{abstract}

Key words : Ectopic pregnancy; laparoscopic; laparotomy.

\section{INTRODUCTION}

Ectopic pregnancy is a leading cause of pregnancy-related death in early pregnancy increasing in incidence worldwide ${ }^{1,2}$. Fortunately, after the advent of high-resolution transvaginal ultrasonography and beta subunit of hCG (beta$\mathrm{hCG}$ ) tests, the accurate diagnosis of ectopic pregnancy(EP) can now be made at an early stage. Late diagnosis, leading in almost all cases to major complications and emergency surgical intervention, is the key factor accounting for high fatality rates in women suffering from ectopic pregnancy in developing countries Surgery remains the mainstay of treatment ${ }^{3}$. Surgical treatments may be radical (salpingectomy) or conservative (milking, salpingostomy), and they may be performed by laparoscopy or laparotomy ${ }^{4}$. Improved anesthesia and cardiovascular monitoring, together with advanced laparoscopic surgical skills and experience, justifies operative laparoscopy for surgical treatment of EP even in women with hemodynamic instability ${ }^{5,6}$. 
The advantage of operative laparoscopy for ectopic pregnancy over laparotomy is well recognized: it is associated with shorter operation times, less intraoperative blood loss, shorter hospital stay, and lower analgesic requirements ${ }^{4,7}$. Significantly fewer adhesions develop in laparoscopic surgery ${ }^{8}$. The laparoscopic approach is also associated with significantly lower costs ${ }^{9}$. We studied the characteristics and outcomes of management of ectopic pregnancy between laparoscopy and laparotomy groups.

\section{MATERIALS AND METHODS}

We conducted a prospective study in two centers: Department of obstetrics and gynecology, BIRDEM hospital and Japan Bangladesh Friendship Hospital (JBFH), Dhaka during the period from November 2008 to October 2012. During this period, there were 89 with a confirmed ectopic pregnancy. These patients were admitted through emergency or outpatient department. The following patient characteristics were recorded: age, parity, body mass index (BMI), gestational age of ectopic pregnancy, and quantitative beta-hCG level,preoperative haemoglobin levels. Conditions that predispose to adhesion formation, including prior surgeries, ectopic pregnancy, history of pelvic inflammatory disease, and endometriosis were recorded. Patients were managed by laparoscopy (number 70) and by laparotomy (number 19). The diagnosis of ectopic pregnancy was based on history, clinical symptoms, physical examination, a positive serum B-human chorionic gonadotropin (B-HCG), transvaginal ultrasonography All surgical procedures were performed by the first author. Linear salphingostomy was the main procedure performed in both groups. Patients were consulted pre-operatively about the surgical procedures and the risks and complications of operations .All operations were conducted under general anesthesia with endotracheal intubation. All the specimens were sent for histopathological examination. Operative procedures: Laparoscopic surgery was performed using three ports. Following the establishment of pneumoperitoneum, a $10 \mathrm{~mm}$ laparoscope was introduced through an $11 \mathrm{~mm}$ cannula in intra-umblical incision. After confirmation of the diagnosis a $5 \mathrm{~mm}$ puncture was made in the left and right lower quadrant using direct visualization Linear salpingostomy was performed by making a linear incision in the antimesenteric border of the affected tube over the tubal swelling with point needle monopolar diathermy. The pregnancy was removed with a forceps, the tube was irrigated Ringer's solution and haemostasis was achieved with bipolar diathermy. The tubal incision was healed by secondary intention. Laparoscopic total salpingectomy was performed by progressive coagulation $\&$ cutting of the fallopian tube starting with the fimbrial end and progressing to the proximal isthmic portion of the tube. Milking of tube (tubal expression) was done for patients with fimbrial EP. The pregnancy was removed from the abdominal cavity via a $10 \mathrm{~mm}$ port.
In the presence of hemoperitoneum, the amount of blood present was assessed by the difference between the amounts of fluid irrigated and evacuated. Laparotomy was performed through a pfannenstiel incision in lower abdomen and standard surgical techniques were applied. Analgesia was prescribed to the patients on demand, namely pethidine $1.5 \mathrm{mg} / \mathrm{kg} \mathrm{I} / \mathrm{M}$ every eight hours or diclofenac sodium $100 \mathrm{mg}$. The following information was collected: estimated blood loss, operative time, operative complications, type of surgery performed, and length of hospital stay. Estimated blood loss was defined as blood loss from the surgery and preexisting blood loss found on entry into the abdomen. Operative time was defined as time between starting and finishing the procedure.Results are presented as mean \pm standard deviation (SD). Continuous variables were tested using the Student $t$ or Mann-Whitney $\mathrm{U}$ test, where appropriate. Numerical variables were tested using the chi-square or Fisher's exact test, where appropriate. A 2-tailed $\mathrm{P}<0.05$ was defined as statistically significant. The statistical calculations were performed with SPSS software (SPSS, Inc., Chicago, Illinois).

\section{RESULTS}

During the study period, 89 patients presented with an ectopic pregnancy. Patients were divided into 2 groups: Group I $(n=70)$ had their EPs removed laparoscopically; Group II ( $\mathrm{n}=19)$ had a laparotomy. A comparison of the demographic and clinical data of the two groups is shown in Table 1. No statistical differences were found in patient age, parity, BMI, gestational age at the time of surgery, preoperative serum $\mathrm{B}-\mathrm{hCG}$, preoperative hemoglobin $\mathrm{Hb}$ )levels. The average time taken for the B-hCG to return to normal $(<20 \mathrm{IU} / 1)$ was 14 days after surgery in both groups. Table 2 shows the predisposing factors of the 2 study groups. No statistical differences were found in frequency of previous surgeries, previous EP, pelvic inflammatory disease(PID), or endometriosis. Table 3 shows the operative outcomes between the 2 groups. Estimated blood loss was significantly lower in the laparoscopy group $(\mathrm{P}<0.0001)$. Only $3(3.81 \%)$ patients in the laparoscopy group required blood transfusion, whereas $16(74.94 \%)$ patients in the laparotomy group needed transfusion $(\mathrm{P}<0.0001)$ The duration of operation was less in laparoscopy group $53.2 \pm 16.8$ minutes than in laparotomy group $84.5 \pm 30.3$ minutes $(\mathrm{P}<0.0001)$. The length of hospital stay following laparoscopic management was significantly less than the laparotomy group $(\mathrm{P}<0.0001)$. Fifty Seven $(72.4 \%)$ in the laparoscopy group did not need analgesia after surgery compared to laparotomy group where all the patients needed analgesia. There were no intraoperative complications in either group. 
Ectopic pregnancy: laparoscopy versus laparotomy

Table 1: Demographic and clinical data of the study groups.

\begin{tabular}{lccc} 
Parameter & $\begin{array}{c}\text { Laparoscopy } \\
(\mathbf{n}=\mathbf{7 0})\end{array}$ & $\begin{array}{c}\text { Laparotomy } \\
(\mathbf{n}=\mathbf{1 9})\end{array}$ & $\mathbf{P}$ value \\
Age (Mean \pm SD), years & $28.7 \square 4.1$ & $30.7 \square 3.6$ & N.S \\
Parity (Mean) & $2.87 \square \pm 1.0$ & $1.45 \pm 1.2$ & N.S \\
beta-hCG & $4282 \pm 2502$ & $5175 \pm 2623$ & NS \\
Gestational age (week) & $7.0 \pm 1.3$ & $7.5 \pm 0.9$ & N.S \\
BMI & $23.1 \pm 4.3$ & $22.9 \pm 3.6$ & N.S \\
Preoperative & $9.06 \pm 2.5$ & $8.4 \pm 3.2$ & NS \\
haemoglobin levels $(\mathrm{mg} / \mathrm{dl})$ & & & \\
\hline
\end{tabular}

Table 2: Predisposing factors of the 2 study groups.

\begin{tabular}{lccc} 
Characteristics n (\%) & $\begin{array}{c}\text { Laparoscopy } \\
(\mathbf{n}=\mathbf{7 0})\end{array}$ & $\begin{array}{c}\text { Laparotomy } \\
(\mathbf{n}=\mathbf{1 9 )}\end{array}$ & P value \\
Previous surgery & $8(21.0)$ & $5(45.4)$ & N.S \\
Previous ectopic pregnancy & $3(7.8)$ & $5(45.4)$ & N.S \\
Previous PID & $2(5.2)$ & $1.3(5.0)$ & NS \\
History of endometriosis & $1(2.6)$ & $1.8(2.8)$ & N.S \\
PID = pelvic inflammatory disease. & & \\
\hline
\end{tabular}

Table 3: Operative outcome in the laparoscopy and laparotomy groups.

\begin{tabular}{lccc}
\hline Parameter & Laparoscopy (70) & Laparotomy (19) & P value \\
Estimated blood loss (ml) & $179.62 \pm 96.7$ & $470.7 \pm 138.4$ & $<0.0001$ \\
Blood transfusion (\%) & $3(3.81)$ & $16(74.94)$ & $<0.0001$ \\
Operative time (min) & & & \\
Procedure performed (n) (\%) & $53.2 \pm 16.8$ & $84.5 \pm 30.3$ & $<0.0001$ \\
Linear salpingostomy & $57(81.4 \%)$ & $11(57.8 \%)$ & NS \\
Salpingectomy & $9(12.8 \%)$ & $7(36.8 \%)$ & NS \\
Milking & $4(5.7 \%)$ & $1(5.2 \%)$ & NS \\
Hospital stay (days) & $1.12 \pm 0.5$ & $5.25 \pm 0.1$ & $<0.0001$ \\
NO need for analgesia (n)(\%) & $57(72.4 \%)$ & 0 & $<0.0001$ \\
$*$ P $<0.0001$ & & & \\
\hline
\end{tabular}

\section{DISCUSSION}

Ectopic pregnancy remains a common gynecologic condition that causes significant maternal morbidity and mortality. The incidence of ectopic pregnancy has increased from $0.5 \% 30$ years ago to a current incidence of $1 \%$ to $2 \%{ }^{10}$. The technical advancement in the field of minimal access surgery has greatly enhanced the possibility of both diagnosing and treating ectopic pregnancy effectively ${ }^{11}$. Since the first excision of a tubal pregnancy through a laparoscope by shapiro \& Adler $^{12}$, it has been used with increasing frequency and the laparoscopic approach for management of EP has replaced laparotomy ${ }^{13,14}$. The predisposing factors, which have been demonstrated in the present study, were almost comparable with those found in a previous studies ${ }^{15,16}$. In the present study the most important symtoms were abdominal pain (96\%), short period of amenorhoea (89.1\%) and vaginal bleeding (79\%). These were comparable with other studies ${ }^{17}$. The use of quantitative measurement of serum concentrations of BHCG together with transvaginal ultrasonography(TVS) has improved the diagnosis of $\mathrm{EP}^{18}$. In laparoscopic group, there was a significant reduction of total blood loss $(\mathrm{P}<0.0001)$, number of patients who needed blood transfusion $(\mathrm{P}<0.001)$, total days needed for hospital stay $(\mathrm{P}<0.0001)$ and the need for postoperative analgesia in the laparoscopic group versus laparotomy group $(\mathrm{P}<0.0001)$. Laparoscopy is not only suitable for early EPS but it is also safe and feasible in instance where there is tubal rupture and hemoperitoneum, provided the patient is not severely compromised hemodynamically ${ }^{19,20}$. These findings were in agreement with previous studies, ${ }^{4,}$, 22. In the present study laparoscopic techniques (salpingostomy or salpingectomy) do not increase the operating time. In fact, it actually saves time, as during a laparotomy, opening and closing the abdomen just to gain access to the affected tube consumes precious operating time. Previous comparative studies support this ${ }^{4,22}$. In the present study we have demonstrated that EPs can be managed successfully via minimal access surgery and Laparoscopic management offer several advantages over conventional treatment via laparotomy (Table 3). It not only results in reduced hospital stay with associated financial savings but also reduced patient morbidity, enabling women to return to their normal activities much sooner ${ }^{4,20}$. In our study the postoperative elimination of hCG was similar in both the laparoscopy and laparotomy-treated patients, whether treated by conservative salpingostomy or radical salpingectomy. In the present study we have demonstrated that, the majority of tubal ectopic pregnancies can be managed laparoscopically. Operative laparoscopy is currently the best treatment for $\mathrm{EP}^{13}$. The benefits to patients are self-evident and our findings are supported in the literature ${ }^{23,24,25,26}$.

\section{CONCLUSION}

Ectopic pregnancy continues to be a life-threatening and sometimes fatal condition, whose treatment frequently requires an emergency intervention. Laparoscopic management offers major benefits superior to laparotomy in terms of less amount of blood loss, less need for blood transfusion, less need for postoperative analgesia and a shorter duration of hospital stay and return to their normal activities much sooner. Laparoscopic management of ectopic pregnancy might be the most beneficial procedure with maximal safety and efficacy.

\section{ACKNOWLEDGEMENT}

We highly acknowledge the strange support of BIRDEM and JBFH, Dhaka, Bangladesh

\section{DISCLOSURE}

All the authors declared no competing interest. 


\section{References}

1. Doyle MB, DeCherney AH, Diamond MP. Epidemiology and etiology of ectopic pregnancy. Obstet Gynecol Clin North Am. 1991;18:1-17. [PubMed].

2. Storeide O, Veholmen M, Eide M, Bergsjo P, Sandvei R. The incidence of ectopic pregnancy in Hordaland County, Norway 1976 -1993. Acta Obstet Gynecol Scand. 1997;76:345-349. [PubMed].

3. Hajenius PJ, Mol BW, Bossuyt PM, Ankum WM, Van Der Veen F. Interventions for tubal ectopic pregnancy. Cochrane Database Syst Rev 2000:CD000324. [PubMed].

4. Murphy AA,Nager CW,Wujek JJ,Kettel JM,Torp VA,Chin HG.Operative laparoscopy versus laparotomy for the management of ectopic pregnancy: a prospective trial.Fertil Steril 1992;57:1180-5].

5. Sagiv R, Debby A, Sadan O, Malinger G, Glezerman M, Golan A. Laparoscopic surgery for extrauterine pregnancy in hemodynamically unstable patients. J Am Assoc Gynecol Laparosc 2001 ;8(4):529-32.

6. Chapron C, Fernandez H, Dubuisson JB. Treatment of ectopic pregnancy in 2000. J Gynecol Obstet Biol Reprod (Paris) 2000 Jun;29(4):351-61 Murphy AA, Nager CW, Wujek JJ, Kettel LM, Torp VA, Chin HG. Operative laparoscopy versus laparotomy for the management of ectopic pregnancy: a prospective trial. Fertil Steril. 1992;57:1180-1185. [PubMed].

7. Gray DT, Thorburn J, Lundorff P, Strandell A, Lindblom B. A cost-effectiveness study of a randomised trial of laparoscopy versus laparotomy for ectopic pregnancy. Lancet. 1995;345:1139-1143. [PubMed]

8. Lundorff P, Thorburn J, Hahlin M, Kallfelt B, Lindblom B. Laparoscopic surgery in ectopic pregnancy. A randomized trial versus laparotomy. Acta Obstet Gynecol Scand. 1991;70:343-348. [PubMed].

9. Langer R, Raziel A, Ron-El R, Golan A, Bukovsky I, Caspi E. Reproductive outcome after conservative surgery for unruptured tubal pregnancy: A 15-year experience. Fertil Steril. 1990;53:227-231. [PubMed].

10. Eltabbakh GH, Piver MS, Hempling RE, Recio FO. Laparoscopic surgery in obese women. Obstet Gynecol. 1999;94:704-708. [PubMed].

11. Ghosh S, Mann C, Khan K, Gupta JK. Laparoscopic management of ectopic pregnancy. Semin Laparosc Surg 1999;6(2):68-72.

12. Shapiro HL, Adler DH. Excision of an ectopic pregnancy through the laparoscope. Am J Obstet Gynaecol 1973; 117:290.
13. Tay J I , Moore J,Walker J J. Ectopic pregnancy: Clinical review BMJ 2000;320(1):916-919.

14. Vasile C, Litta P, Sacco G, Minante M.Laparoscopic surgical approach to ectopic pregnancy. Clin Exp Obstet Gynecol 1999;26(1):35-8.

15. Pisarska MD, Carson SA, Buster JE. Ectopic pregnancy. Lancet 1998; 351: 1115-1120.

16. Mitchell DE, McSwain HF, McCarthy JA, Peterson HB. Hysterosalpingographic evaluation of tubal patency after ectopic pregnancy. Am J Obstet Gynecol 1987; 157: 618-622.

17. Leach RE, Ory SJ. Modern management of ectopic pregnancy. J Reprod Med 1989; 34: 324-338.

18. Ankum WM, Hajenius PJ, Schrevel LS, van der Veen F. Management of suspected ectopic pregnancy. Impact of new diagnostic tool in 686 consecutive cases. J Reprod Med 1996; 41: 724-728 19. Maruri F, Azziz R. Laparoscopic surgery for ectopic pregnancies: technology assessment and public health implications. Fertil Steril 1993; 59:487.

20. Baumann R, Magos AL, Turnbull A. Prospective comparison of videopelviscopy with laparotomy for ectopic pregnancy. Br J Obstet Gynaecol 1991; 98:765.

21. Vermesh M, Silva PD, Rosen GF, Stein AL, Fossum GT, Sauer MV. Management of unruptured ectopic gestation by linear salpingostomy: A prospective, randomized clinical trial of laparoscopy versus laparotomy. Obstet Gynecol 1989; 73: 400-403.

22. Brumsted J,Kessler C,Gibson C,Nakajima S,Riddick DH,Gibson M.A comparison of laparoscopy and laparotomy for the treatment of ectopic pregnancy.Obstet Gynecol 1988;71:889-92.

23. Takeda A, Manabe S, Mitsui T, Nakamura $H$. Management of patients with ectopic pregnancy with massive hemoperitoneum by laparoscopic surgery with intraoperative autologous blood transfusion. J Minim Invasive Gynecol. 2006; 13:43-8. [PubMed].

24. Hsu S, Mitwally MF, Aly A, Al-Saleh M, Batt RE, Yeh J. Laparoscopic management of tubal ectopic pregnancy in obese women. Fertil Steril 2004;81:198-202. [PubMed].

25. Yamada T, Okamoto Y, Kasamatsu H, Mori H. Intraoperative autologous blood transfusion for hemoperitoneum resulting from ectopic pregnancy or ovarian bleeding during laparoscopic surgery. JSLS. 2003;7:97-100. [PMC free article] [PubMed].

26. Mohamed H, Maiti S, Phillips G. Laparoscopic management of ectopic pregnancy: a 5-year experience. J Obstet Gynaecol. 2002;22:411-414. [PubMed]. 